\title{
Travel Behavior of Car Travelers with the Presence of Park-and-Ride Facilities and Autonomous Vehicles
}

\author{
Jamil Hamadneh*, Domokos Esztergár-Kiss \\ 1 Department of Transport Technology and Economics, Faculty of Transportation Engineering and Vehicle Engineering, \\ Budapest University of Technology and Economics, H-1111 Budapest, Múegyetem rkp. 3., Hungary \\ * Corresponding author, e-mail: jamil.hamadneh@kjk.bme.hu
}

Received: 10 February 2021, Accepted: 28 April 2021, Published online: 01 October 2021

\begin{abstract}
Travelers' behavior is predicted based on their individual preferences. People search for alternatives to maximize their benefit from doing activities, such as increasing the activity time by minimizing the travel time. Traffic congestion and the scarcity of parking spaces in the city center motivate the decision-makers to encourage travelers to use the park-and-ride (P\&R) system. An evaluation concerning the impact of using the P\&R system on the travel behavior of car users is conducted. Some of the existing P\&R facilities are incorporated into the daily activity plans of car travelers to produce new daily activity plans (i.e., P\&R facility is considered an activity). By using the MultiAgent Transport Simulation (MATSim) open-source tool, simulations of the daily activity plans including the P\&R system and autonomous vehicles (AVs) are conducted. The study examines three scenarios: (1) a simulation of the existing condition, (2) a simulation of the daily activity plans of the travelers with the P\&R system, and (3) a simulation of the daily activity plans of the travelers with the P\&R system and AVs. The results show that using the P\&R system increases the overall travel time compared with the existing conditions, and the use of AVs as a transport mode impacts the existing modal share as follows: $64 \%$ of the car users switch to AVs, while $15 \%$ of the car users switch to public transport. The output of this study might be used by policy-makers in parking pricing and the location of the P\&R facilities.

Keywords
\end{abstract}

autonomous vehicle, optimization, park and ride, utility function

\section{Introduction}

As stated by Mokhtarian and Salomon (2001), travel time is considered a derived demand, which is an economic term. The derived demand means that people travel to conduct an activity, to get benefit, while the travel itself is considered as a waste (Mokhtarian and Salomon, 2001). Throughout the years, traffic congestion is steadily increasing due to the continuous population growth and the rise in car ownership. Decision-makers work to alleviate the traffic congestion by using different transport strategic plans, such as encouraging travelers to choose public transport, multimodal, non-motorized mode, and to use advanced technology, which makes the traveling easier. The remedial actions that make changes at traffic congestion level are parking pricing, increasing the accessibility of public transport, and providing park-and-ride (P\&R) facilities on the periphery of the city center, close to public transport stations (Ortega et al., 2020a). Usually, people who work in the city center and use their personal cars face several problems regarding parking restrictions, which enforce travelers to park their cars outside the city center and to use other transport modes to reach their work and to avoid extra cost (Ortega et al., 2020b). For example, public transport, taxi, car-sharing, and non-motorized modes are alternatives for personal cars in the city center (Parkhurst, 2000). In the meanwhile, the P\&R system, which provides travelers (especially commuters) with incentives to save cost by leaving their cars at specific locations and using the adjacent public transport mode instead, is developed (Song et al., 2017). The saved cost is generated from the lack of parking costs and fuel consumption as well as other indirect benefits, such as removing the congestion stress and the time for searching a vacant parking space. It is mentioned in the literature that travelers seek options which make them maximize their utility based on their preferences; examples for the options which travelers look for include minimum time, minimum cost, a suitable level of comfort, and safe travel (Horni et al., 2016). The advancement in 
technology is uninterrupted, and a recent innovation is the autonomous vehicle (AV), which appears on the market soon (Musk, 2020). The AV is a demanding and hot topic, and before introducing it to the market, more efforts are needed to understand the impact of this technology on the daily life of people (Litman, 2017). An AV is different from a conventional car, such as using AV is considered as a door-to-door service, AV does not need a driver to operate, and to be used, AV does not require a driving license. An AV can be operated shared and unshared, and the travel time is suggested to be minimized due to the decrease in car ownership (Menon et al., 2019). In this paper, as AVs are not on the market, the value of travel time (VOT) of travelers is used to differentiate among the transport modes. People choose transport modes based on the VOT, which is defined as the ratio of the marginal utility of the travel time to the marginal utility of the cost spent in a transport mode (Hensher and Greene, 2003; Horni et al., 2016). Thus, the VOT of AV is suggested to be less than a conventional car's because people can multitask onboard as they do not have to sit behind the steering wheel to control the driving (Wiseman, 2017). In this research, the P\&R system and AVs are integrated to study their impacts on the travel behavior of car users.

The contribution of this study is to evaluate the change in the modal share of the car users when a fixed fleet of $\mathrm{AVs}$ is provided and rules do not enforce car users to park their cars in the 13 locations of P\&R facilities. The simulation is conducted based on existing P\&R facilities in Budapest city, Hungary, and it assumes a smaller VOT of AV than that of a conventional car (Steck et al., 2018). In this study, the P\&R facilities and AVs are integrated and simulated with the existing public transport system. In this regard, three scenarios are carried out, as follows:

1. A simulation of the existing condition (i.e., the travelers' daily activity plans)

2. A simulation of the daily activity plans of the travelers including the P\&R system (i.e., the travelers' new daily activity plans)

3. A simulation of the daily activity plans of the travelers considering P\&R and AVs, where a tradeoff between car, public transport, and AV is conducted (i.e., Scenario (2) when AVs are on the market, and a parking fee is applied)

\section{Literature review}

The P\&R system is used to alleviate the traffic congestion in the city center and to encourage the use of public transport. Generally, the locations of P\&R facilities are designed to be as close to public transport terminals as possible. The target group of the P\&R system is car users, especially the commuters, which is the examined group of this research, too. Parking supply is determined based on the demand for parking, as stated by Al-Sahili and Hamadneh (2016). Decisionmakers propose strategies that regulate the parking use in the city by issuing laws, such as parking is allowed for a maximum of three hours to increase the turnover of parking (Garber and Hoel, 2014). Travelers with a short stay in the city center do not prefer to use the P\&R system, while travelers with a long stay in the city center are much interested in using the P\&R system. To select a place to construct a P\&R facility, a simulation study is needed to see how travelers behave and what the consequences are. Moreover, the determination of the capacity of the P\&R system's facilities is important to ensure an effective system. In this section, some related papers are discussed.

In their study, Du and Wang (2014) present the optimal number of P\&R facilities, capacity, and locations by using Modal Choice formulation based on the lowest-cost route. A Multi-objective Spatial Optimization model is developed and applied by Farhan and Murray (2008) to find locations for P\&R facilities with optimal benefits. The results of the study suggest the reallocation of the existing P\&R facilities and the building of new facilities (Farhan and Murray, 2008). A Modal Choice formulation is developed and applied on private vehicles, buses, and the P\&R system by Cavadas and Antunes (2019) to aid the identification of a new P\&R facility's properties in the city of Coimbra. Each P\&R facility regardless of its capacity has a catchment area that can be calculated by using different methods, as shown in a study by Mesa and Ortega (2001). A geographical model and a mathematical model - together or in separate - can be used to estimate the size of a P\&R facility (Memon et al., 2014). Memon et al. (2014) use various mathematical models to define the catchment area boundaries, such as a geometric shape, parabola, circle, etc. Duncan and Christensen (2013) state that the geographic method is applied to define the catchment area of a P\&R facility by using the distance of the travel and the time. Similarly, Farhan and Murray (2005) use the time, the cost, and the fee to calculate the boundary of the catchment area of a P\&R facility. It is worth mentioning that the $P \& R$ system is influenced by several factors including the quality of the public transport system, the location of P\&R facilities, and the congestion level (Spillar, 1997).

$\mathrm{AV}$ is a new technology that might be on the market in the following years, as stated by (Musk, 2020). This technology with its characteristics can impact the land 
use since the use of AVs saves lands for other uses than parking. Moreover, AVs can affect the size of P\&R facilities because it decreases the number of conventional cars on the market (i.e., car ownership), and AV is driven by a machine not a human; it either parks itself or goes to pick another passenger up (Hamadneh and EsztergárKiss, 2019; Hamadneh and Esztergár-Kiss, 2021). People's acceptance of ridesharing means that they favor the use of AVs (Bansal et al., 2016). Moreover, a study conducted in six European countries show different acceptance level of the AVs based on various factors, such as time, cost, income, and gender (Etzioni et al., 2020). Travelers' preferences, such as trip purpose, trip time, trip cost, income, gender, age, and the acceptability of waiting time, influence the use of AVs (Golbabaei et al., 2020). In the meantime, people seek those travel options that maximize their utility. An AV has a lower disutility than conventional cars since travelers can conduct onboard activities instead of driving the car (Pudāne et al., 2018).

In reality, cars have higher accessibility than the public transport mode, so replacing public transport with cars is not a feasible solution nor realistic due to the capacity of roads, the cost of infrastructure, and scarcity of lands. In case of AVs, lands are saved (Vleugel and Bal, 2018), infrastructure in the long term is saved (Anderson et al., 2016), the capacity of roads is increased (Olia et al., 2018), which consequentially, increases the accessibility (Meyer et al., 2017). One of the disadvantages of AVs is that travelers are exposed to a waiting time, which depends on the penetration of AVs into the market and the time of the day (i.e., peak hours or off-peak hours). However, travelers can track the location of $\mathrm{AVs}$ and wait either inside or outside; it provides a better option than walking to the nearest public transport stop and wait there (Bischoff and Maciejewski, 2016). The acceptable waiting time for AVs is supposed to be less than or equal to the time needed for walking and waiting at public transport stops or the time needed for parking a car (Bischoff and Maciejewski, 2016). The acceptable waiting time, which can be used to govern the fleet size and does not influence the people's acceptability of AVs, is 10 minutes, as stated by Hörl et al. (2016) and Bischoff and Maciejewski (2016).

An agent-based modeling called MATSim (MultiAgents Transport Simulation), which uses a co-evolutionary algorithm, is applied to simulate the daily activity plans of travelers at a microsimulation level (Horni et al., 2016). MATSim has the ability to simulate large projects with a capacity reaching up to $10^{\wedge} 7$ agents in a shorter time compared with other software (Nicolai, 2013). Several studies focusing on AV and its impact on the mobility of travelers are conducted by using MATSim. Bischoff and Maciejewski (2016) state that one unshared AV can replace ten conventional cars, and one shared AV can replace six conventional cars. Boesch et al. (2016) declare that the waiting time impacts the fleet size of AVs. The authors demonstrate that the fleet size of AVs can be reduced by a maximum of $90 \%$ based on the waiting time. When Bischoff et al. (2019) conduct a study to find the effects of AVs on the demand-responsive transport (DRT), the scholars use 10 minutes as the acceptable waiting time for AVs. Leich and Bischoff (2019) simulate shared autonomous vehicles (SAVs), and they show that the first riders should have a waiting time not more than 10 minutes, considering the number of passengers in the path of the vehicle. Fagnant et al. (2016) demonstrate that 9.3 conventional cars can be replaced by one SAV (the capacity is four passengers) with a minimal waiting time, based on a study conducted in the urban areas of the city of Austin. The study of Hamadneh and Esztergár-Kiss (2019) shows that eight conventional cars can be replaced by one SAV, where the average waiting time is $7-10$ minutes. Ortega et al. (2020a) study the impact of the P\&R system on the travel behavior of shoppers and workers. The authors replace the public transport by AVs, and they conclude that an AV trigger the enhancements of the travel time and the traveled distance.

Studies related to AVs, the P\&R system and their impacts on the travel behavior, are scarcely found in the literature. This research is conducted to add a new contribution to this insufficiently analyzed topic. The MATSim is used in this study due to its flexibility and the suitability for the scope of this study. MATSim is based on an activity-based model; thus, the travelers' trips are simulated by using their daily activity plans, and the maximization for the utility is obtained.

\section{Methodology}

The sample size is taken from the Hungarian Census Bureau in 2014, which conducts a periodic study every 10 years (HCSO, 2018). The sample size consists of 2309 travelers who usually use their cars to reach the place of their daily activities. Budapest, which is the place of the study, is considered the largest city in Hungary as it contains more than $18 \%$ of the gross population of the country (HCSO, 2018). The obtained data contain the daily activity plans of the travelers, information about the travelers' sociodemographic variables, and the trip characteristics, such as the transport mode, the trip purpose, the 
income, the age, the duration and the schedule of the trips as well as the parking fees and time. It is worth mentioning that the sample size of this study is taken from a large sample size of different transport modes, where the large sample size contains 8500 travelers. Table 1 shows the composition of the sample size. Those people who travel for work as a first destination forms $69.64 \%$, who go for shopping is $7.54 \%$, who travel to conduct leisure activity is $3.38 \%$, who travel to the place of education is $7.8 \%$, and who go for other destinations is $11.61 \%$. Thus, it can be concluded that the majority of the travelers go to work.

The collected data are studied, organized, and converted into XML files to be used in MATSim. Fig. 1 illustrates three scenarios. The first scenario, Scenario (1), simulates the existing situation, where travelers record their actual daily activities. Scenario (2) includes the integration of the P\&R system into the daily activity plans of the car users, where the drivers must park their cars in the P\&R facility closest to their destination (i.e., using P\&R facility is mandatory). Scenario (3) includes a tradeoff between using the P\&R system and switching to AV (i.e., using P\&R is not mandatory).

Fig. 2 illustrates the characteristics of the case study, which contains 23 districts, where each district is divided into smaller zones. Budapest has 1178 zones, and the number of $\mathrm{P} \& \mathrm{R}$ facilities in the city is 31 ; however, only 13 locations of P\&R facilities are used based on ArcGIS and Google Maps Directions API Service tools, which are applied to identify the locations of the P\&R facilities and the travelers using the real road network measurements (Mesa and Ortega, 2001).

The methodology is based on maximizing the utility of the travelers by changing at least one parameter of the various trip characteristics, such as the transport mode, the departure time, or the activity chain (Horni et al., 2016). For this purpose, the MATSim tool is selected, where the daily activity plans of car travelers are simulated and optimized. The daily activity plans of the travelers consist of two parts: the traveling part and the activity part. The traveling part includes the used transport mode, the departure time, and the arrival time, while the activity part includes

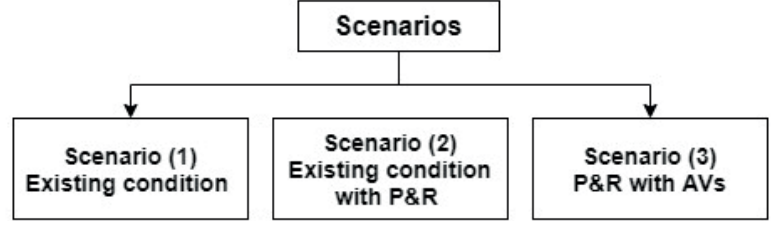

Fig. 1 The three scenarios of simulations

the duration of an activity and the opening hours of that activity. Travelers select a transport mode based on their preferences. However, in this research, the daily activity plans are taken from actual data, and the transport mode selection is based on travel time and travel cost. Travelers select a transport mode to maximize their utility generated from both the activity and the travel parts. In MATSim, the activity plans are evaluated and simulated to maximize the utility of the travelers, where MATSim is built based on a genetic algorithm (GA). In the GA, the daily activity plans go through a mutation and cross over steps to generate new daily activity plans, where the utility of the travelers is maximized based on preset parameters, such as the cost of the travel per transport mode, the utility of arriving late/early, the utility of leaving early, and the utility of the activity duration (Horni et al., 2016; Arnott et al., 1993).

The required input files of MATSim contain the road network, the vehicle characteristics, the facilities, the population, the public transport network, and its schedule. The road network as well as the public transport lines and schedules are taken from OpenStreetMap (OSM) and BKK by using JOSP MATSim plugin (JOSM, 2018).

The MATSim tool applies the co-evolutionary algorithm through conducting an iterative loop. This loop includes MobSim, Scoring, and re-planning in this sequence. The loop is conducted until reaching a steadystate condition or a state where no further benefit can be earned from changing the plans (Horni et al., 2016). MobSim is used to load the travelers on the network and to simulate their trips based on their initial activity plans. Dijkstra's routing algorithm in MATSim is applied to find the best route, where MobSim uses the Qsim engine to load the plans on the road network. MobSim applies the first in first out (FIFO) traffic strategy to demonstrate the

Table 1 Sample size characteristics*

\begin{tabular}{|c|c|c|c|c|c|c|}
\hline & & \multicolumn{5}{|c|}{ Activity type (\%) } \\
\hline & Sample size & Work & Shopping & Leisure & Education & Others \\
\hline $\begin{array}{l}\text { Daily activity } \\
\text { plans of travelers }\end{array}$ & 2309 & $69.64 \%$ & $7.54 \%$ & $3.38 \%$ & $7.80 \%$ & $11.61 \%$ \\
\hline
\end{tabular}

*Home-based activity 


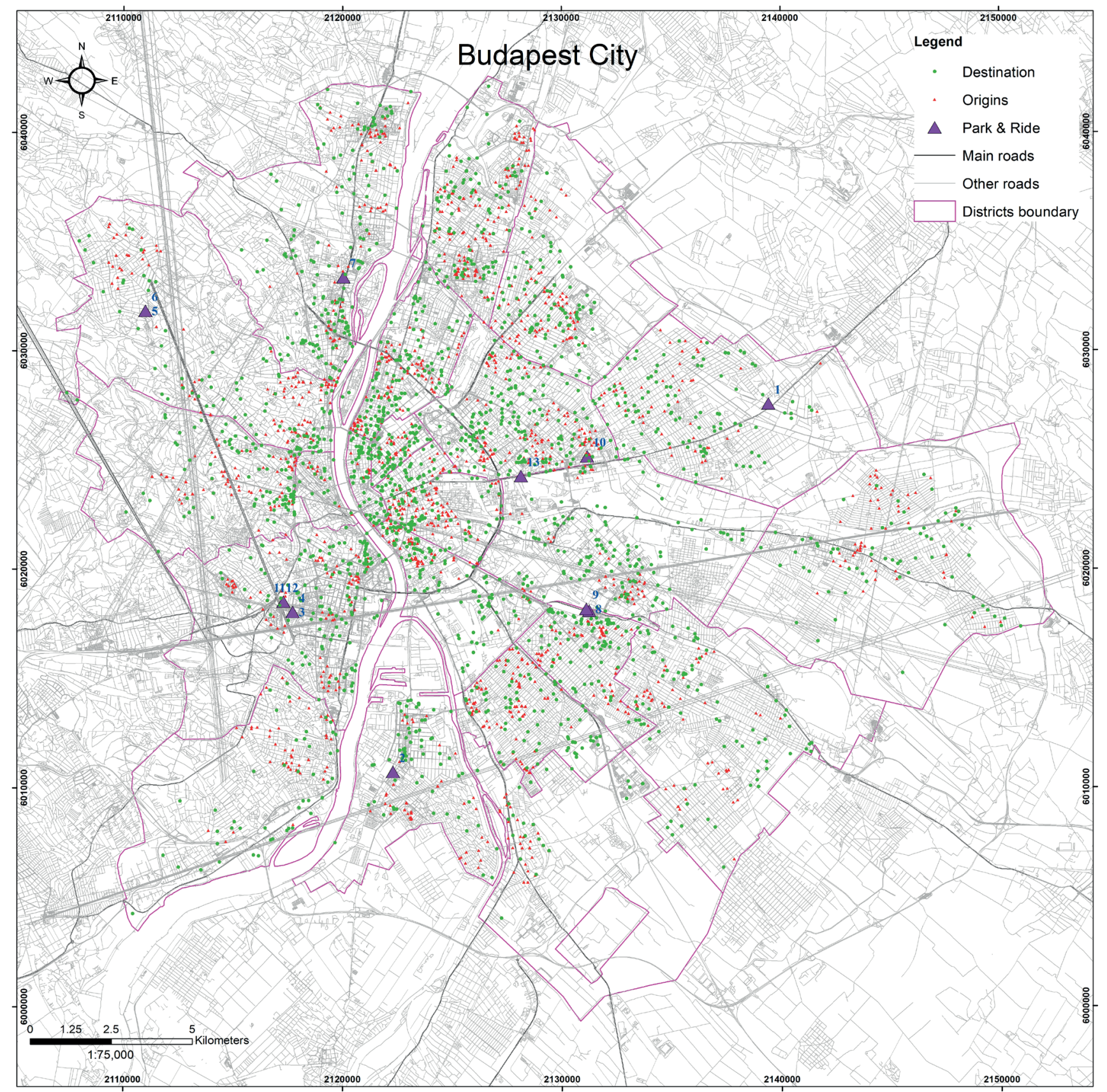

Fig. 2 Case study: Budapest network and the location of P\&R facilities

road capacity factors. Technically, the MATSim default transport mode is the conventional car, while other transport modes can be related to the default mode can be used in a process called teleportation, which depends on time, speed, and distance factors (Horni et al., 2016). In the scoring section, the selected activity plans take a score based on Eq. (1), which is the utility function and sums both the activity time and the travel time. This utility function is the Charypar-Nagel function, and it is found in the scoring step of MATSim (Charypar and Nagel, 2005). Equation (1) is the general equation that combines both travel and activity time, where the result is a number called the score value.

$$
\mathrm{U}_{\text {plan }}=\sum_{i=0}^{n}\left(\mathrm{U}_{\mathrm{act}, i}+\mathrm{U}_{\text {trav }, i}\right)
$$

$\mathrm{U}_{\text {plan }}$ is the utility of a selected activity plan, and $\mathrm{U}_{\text {act }}, i$ is the utility of conducting an activity. The score of travel is negative, while the score of conducting an activity is always positive since it means earning money rather than spending.

In the re-planning process, by making changes to the initial plans, such as the departure time, the transport modes, 
and the route, travelers can improve their plans in each iteration to reach a steady-state condition. After the re-planning step, the new daily activity plans (i.e., changes occurred on the initial one in the re-planning step) are re-simulated through MobSim to be re-scored again. Afterwards, the selection of a plan is carried out by Logit model probability (Horni et al., 2016). The Multinomial Logit (ML) model is used to select a plan out of the generated daily activity plans. The ML is used to compute the probability of a traveler to use a certain transport mode, based on the distribution of the utility function (Simoni et al., 2018). The re-planning step is where a mutation and the selection of a plan are executed (i.e., GA) to generate a better solution rather than the optimum one. It is worth mentioning that the scoring depends on several factors like the time and the cost as well as the Vickrey bottleneck model parameters (Charypar and Nagel, 2005; Arnott et al., 1993). The Vickrey bottleneck model parameters include the following utilities for traveling, waiting, and being late: $-12 / \mathrm{h},-6 / \mathrm{h}$, and $-18 / \mathrm{h}$ for $\beta_{\text {trav }}, \beta_{\text {wait }}$, and $\beta_{\text {late.ar, }}$ respectively (Arnott et al., 1993). Generally, the dynamic vehicle routing problem (DVRP) algorithm is applied for simulating AVs to match the travelers, and DVRP is integrated in MATSim (Horni et al., 2016; Maciejewski, 2016). The simulation includes the operational parameters when AVs are simulated with a passenger drop-off time of 60 seconds and a pick-up time of 120 seconds (Bischoff et al., 2019). People choose AVs once they realize that using AVs means the maximization of their benefits, which can be shown by the VOT, people's acceptability, comfort, trust, and safety (Golbabaei et al., 2020).

\section{Results}

The daily activity plans of the car users are studied based on three scenarios. Each scenario is discussed, as shown in the following subsections.

\subsection{Scenario (1): the simulation of the daily activity plans of the car users}

Scenario (1) studies the existing condition of the car users' travel behavior without considering the P\&R system. MATSim is used in the simulation of 2309 travelers' trips to find some mobility indicators, such as travel distance and travel time, as shown in Table 2. The average trip distance is $8.78 \mathrm{~km}$, and the average trip time is 35.5 minutes. The trip time do not contain the average parking time (i.e., searching for an empty parking space, parking, and walking to the destination/activity location).
Table 2 The mobility indicators of the travelers in Scenario (1).

\begin{tabular}{lccc}
\hline Scenario & $\begin{array}{c}\text { Average leg } \\
\text { distance }(\mathrm{km})\end{array}$ & Average trip time & $\begin{array}{c}\text { Total daily travel } \\
\text { time }\end{array}$ \\
\hline$(1)$ & 8.78 & $00: 35: 30$ & $1: 28: 03$ \\
\hline
\end{tabular}

Based on the information provided by the travelers, it can be concluded that the parking process as an average value for all is around 8.5 minutes. Thus, the average trip time is 44 minutes (i.e. 35.5 plus 8.5 ). The total travel time per day equals the number of trip legs multiplied by 44 minutes, which is 88.05 minutes.

\subsection{Scenario (2): the simulation of the daily activity plans with the presence of the $P \& R$ system}

Scenario (2) presents the situation where travelers have to park their cars in the P\&R facilities closest to their destinations. It is good to know that the locations of P\&R facilities are close to public transport terminals, which makes the travelers' switch to the public transport after they arrive at the P\&R facilities easier. The P\&R system is integrated into the daily activity plans of the travelers, where each facility of $P \& R$ is considered as a separate activity with a 5 minutes duration that simulates the parking time needed to park a car without the searching time (Ortega et al., 2020a). It is worth mentioning that the P\&R facilities are allocated to the travelers by using the Google API routing algorithm. The simulation of the new daily activity plans (including the P\&R activity) is conducted until a steady-state for the system is reached. The results show an average leg travel distance of $3.36 \mathrm{~km}$, which represents one trip from one activity to another during the day, and the average trip time is 28.5 minutes, as shown in Table 3. The total daily travel time per traveler is 114 minutes (calculated as the average trip time multiplied by the average number of legs/trips in the daily activity plans of the travelers). It is shown that the average trip time is smaller than in Scenario (1) because the distance to the destination is shortened by inserting P\&R facilities in between. On the contrary, the total travel time is larger than in Scenario (1) because the travelers change the transport mode to a slower one as well as there is an increase in the total travel distance due to the diverted routes taken to reach $\mathrm{P} \& \mathrm{R}$ facilities.

Table 3 Travelers' trip time components for Scenario (2), when a P\&R system is integrated.

\begin{tabular}{lccc}
\hline Scenario & $\begin{array}{c}\text { Average leg } \\
\text { distance }(\mathrm{km})\end{array}$ & Average trip time & $\begin{array}{c}\text { Total daily travel } \\
\text { time }\end{array}$ \\
\hline$(2)$ & 3.36 & $00: 28: 30$ & $1: 54: 00$ \\
\hline
\end{tabular}




\subsection{Scenario (3): the simulation of the daily activity plans with the presence of $P \& R$ and $A V s$}

The presence of AV impacts the modal share of the existing condition of Scenario (2). In Scenario (3), fleet size of AVs, which equals the $20 \%$ of the number of travelers, is inserted into the network with the conventional cars and public transport. The cost of using a car is increased by $10 \%$ to demonstrate the increase in the travel cost due to the parking pricing as well as to motivate people to use the P\&R system and switch to public transport. The marginal utility of traveling by AV is $60 \%$ of the conational car's, as shown by previous studies (Steck et al., 2018; Bozorg, 2016). The simulation is run, and the results present changes in the existing modal share and in the travel measures like time and distance. Referring to the definition of Scenario (2), the modal share is $50 \%$ public transport and $50 \%$ car, where the access and egress time are merged with public transport. The inclusion of an AV into the system leads to a change in the modal share based on the utility of the travelers (i.e., maximizing their score concerning the time and the cost). The new modal share is $21 \%$ car, $15 \%$ public transport, and $64 \%$ AV. Moreover, the total number of requests that are served by the AV fleet is 2823 orders (i.e., trips), and $33 \%$ of them exposes to a maximum of 10 minutes waiting time.

Table 4 summarizes the output of the simulation of the AV fleet size being $20 \%$ of the sample size. The trip time is 26.75 minutes, the occupied time is 7255.15 hours for the AV fleet, and the travelers' pick-up and drop-off times are 99.80 hours and 49.83 hours, respectively. The sum of the pick-up, the drop-off, and the occupied time represents the total occupied time, and the ratio of the empty driven time to the total occupied time shows the fleet utilization index and consequently, gives an indication of the additional vehicle miles traveled (VMT) compared with conventional cars. The fleet utilization equals $96 \%$, which means that the used fleet of AV is occupied by passengers all the time. It is worth mentioning that another fleet size is simulated which represents around the $40 \%$ of the number of travelers (i.e., $1000 \mathrm{AVs}$ ), and the results demonstrate the impact of AVs appearing on the market on the modal share. It is demonstrated that as the AV fleet size increases, more travelers switch to AV. It is found that with a fleet size of $1000 \mathrm{AVs}$, around 4150 trips are served, while around 2823 trips in case of 460 AVs fleet size (i.e., the $20 \%$ of the sample size). Additionally, in the case of 460 AVs, around $33 \%$ wait 10 minutes compared to the $55.1 \%$ in case of the $1000 \mathrm{AVs}$ fleet size.

\section{Discussion}

The daily activity plans of those travelers who use personal cars to reach their daily activities are simulated in this paper by using the MATSim open-source tool. The simulations are summarized in three scenarios:

Scenario (1) includes the simulation of the existing condition and provides the actual travel time and travel distance of the travelers. Scenario (1) aims to study the existing travel behavior of the travelers, such as knowing the travel time, the travel distance, and to optimize the daily activity plans of the travelers without changing the transport mode. The travelers in this scenario do not consider the P\&R system or AVs, which might lead to such indirect impacts as the reduction of traffic congestion, air pollution, and stress generated from the congestion and the scarcity of parking spaces.

Scenario (2), which presents a solution for the scarcity of parking spaces, alleviates the congestion by reducing the number of vehicles on the road network and removes the stress accompanied with the searching time for empty parking spaces. The result of the simulation demonstrates longer distances and longer travel time than in Scenario (1). The output of Scenario (2) is useful for decision-makers to find the motivations and the incentives, such as pricing zone (i.e., buffer), road tolls, discount on using public transport, and parking pricing strategy, to encourage travelers to use P\&R facilities or to compensate for the extra driven time.

Scenario (3) studies the impact of the inclusion of AVs on the market with the conventional transport modes (i.e., car and public transport), when P\&R facilities are integrated into the daily activity plans of the travelers. The results show a notable change in the modal share because the AV is treated differently than a conventional car, such as the valuation of travel cost is less due to the ability to multitask on the board of an AV and other phycological benefits (e.g., less driving stress and tension) are present, too. The output of the simulation demonstrates that the travelers travel longer distances than in Scenario (1) due to the empty driven distances, and the used AVs fleet size

Table 4 The travelers' trip time components for Scenario (3), when an AV fleet is used.

\begin{tabular}{|c|c|c|c|c|c|c|c|}
\hline Scenario & Fleet size & Average trip time (min) & Occupied time (hr) & Empty driving time (hr) & Drop-off time (hr) & Pick-up time (hr) & Stay (hr) \\
\hline (3) & 460 & $00: 26: 45$ & 7255.15 & 273.55 & 49.83 & 99.80 & 4173.77 \\
\hline
\end{tabular}


have high utilization that makes only $33 \%$ wait an average 10 minutes. The locations of P\&R facilities in the network cause a large percentage shift from public transport to AV. The modal share of public transport when using P\&R system is mandatory is $50 \%$, and when apply parking pricing the modal share drops from $50 \%$ to $15 \%$.

The traffic condition is not enough to encourage people to use the P\&R system. Some travelers, for example have a parking garage at their properties or workplaces; thus, parking pricing in the city center is efficient for travelers who do not have personal parking spaces. In this study, the assumption is made that all travelers are affected by the parking pricing (i.e., the increment in the travel cost due to the increase in the parking fees), while come travelers might not affected by the parking pricing because they have private parking. In addition, parking pricing might be applied for certain zones and not for the whole city center. It is recommended to make a study in the future, in which the two types of workers regarding the parking ownership are separated. Optimizing and upgrading the existing and proposed P\&R facilities are effective in reducing the travel time, which needs further studies with a focus on the optimization of the locations and the capacities of these facilities. More efforts are needed to see what extra benefits can be got when travelers drive longer distances than usual driven distances. Moreover, parking a car at the workplace/destination, or entering the city center and paying the parking fees, the state restricting on parking time, or entering a zone are different conditions that need to be studied. The outcome of this study can be used by policy-makers, who decide about the strategy of the P\&R system, such as its capacity, its cost of use, the incentives, and the operational use.

In essence, managing the parking in the city center can be done by using the P\&R system. The P\&R system increases the travel time, the travel distance, and the emissions due to the extra distance (assuming that public transport is not electric). The AVs can attract travelers and make them avoid using the P\&R system, which reduces the number of conventional cars and the area needed for P\&R facilities. All of these are controlled through the parking pricing strategies set by the decision-makers.

\section{Conclusion}

Innovation in transportation industry is continuously introduced to provide a more beneficial mobility for people. In this research, the travel behavior of car users is studied through three scenarios: (1) the existing condition which includes the conventional transport modes, (2) the simulation of the existing condition with the integration of the P\&R system using the conventional transport modes, (3) the simulation of the daily activity plans of the travelers concerning the P\&R system and AVs. The simulations of the previous scenarios are conducted by using an open-source software called MATSim, which applies co-evolutionary algorithm. The integration of both the P\&R system and AVs into the daily activity chain of the travelers aims to evaluate the P\&R system with the presence AVs. The city center of Budapest has restrictions on using parking, and there is a scarcity of parking spaces due to the old buildings and the narrow roads. These problems might be solved by the use of the P\&R system and AVs. The simulation of Scenario (3) shows a decrease in the travel time once AVs appear on the market. Based on the result of this study, the benefits of using AVs are the elimination of the parking time and the parking cost as well as the minimization of the travel time. Consequentially, saving lands, for example by reducing the number of on-street parking, is obtained in the AVs era. The results show that using the P\&R system increases the overall travel time, compared with using a conventional car (i.e., the existing condition). The results demonstrate that using AVs as a transport mode impacts the existing modal share concerning the VOT of AV and the conventional cars', too. In conclusion, the impact of the P\&R system and the AVs on the travel behavior and the modal share of certain travelers is evaluated in this paper.

\section{Acknowledgment}

The research reported in this paper and carried out at the Budapest University of Technology and Economics has been supported by the National Research Development and Innovation Fund (TKP2020 Institution Excellence Subprogram, Grant No. BME-IE-MISC) based on the charter of bolster issued by the National Research Development and Innovation Office under the auspices of the Ministry for Innovation and Technology.

The research was supported by the BKK Centre for Budapest Transport, providing travel data collected through the EFM Unified Transport Model of Budapest.

The linguistic revision of this paper is prepared by Eszter Tóth. 


\section{References}

Al-Sahili, K., Hamadneh, J. (2016) "Establishing parking generation rates/ models of selected land uses for Palestinian cities", Transportation Research Part A: Policy and Practice, 91, pp. 213-222. https://doi.org/10.1016/j.tra.2016.06.027

Anderson, J. M., Nidhi, K., Stanley, K. D., Sorensen, P., Samaras, C., Oluwatola, T. A. (2016) "Autonomous Vehicle Technology: A Guide for Policymakers", Rand Corporation, Santa Monica, CA, USA.

Arnott, R., De Palma, A., Lindsey, R. (1993) "A Structural Model of Peak-Period Congestion: A Traffic Bottleneck with Elastic Demand", The American Economic Review, 83(1), pp. 161-179. [online] Available at: https://www.jstor.org/stable/2117502 [Accessed: 09 February 2021]

Bansal, P., Kockelman, K. M., Singh, A. (2016) "Assessing public opinions of and interest in new vehicle technologies: An Austin perspective", Transportation Research Part C: Emerging Technologies, 67, pp. 1-14.

https://doi.org/10.1016/j.trc.2016.01.019

Bischoff, J., Führer, K., Maciejewski, M. (2019) "Impact assessment of autonomous DRT systems", Transportation Research Procedia, 41, pp. 440-446.

https://doi.org/10.1016/j.trpro.2019.09.074

Bischoff, J., Maciejewski, M. (2016) "Simulation of City-wide Replacement of Private Cars with Autonomous Taxis in Berlin", Procedia Computer Science, 83, pp. 237-244. https://doi.org/10.1016/j.procs.2016.04.121

Boesch, P. M., Ciari, F., Axhausen, K. W. (2016) "Autonomous Vehicle Fleet Sizes Required to Serve Different Levels of Demand", Transportation Research Record: Journal of the Transportation Research Board, 2542(1), pp. 111-119. https://doi.org/10.3141/2542-13

Bozorg, S. M.A. S. L. (2016) "Potential Implication of Automated Vehicle Technologies on Travel Behavior and System Modeling", PhD Thesis, Florida International University.

Cavadas, J., Antunes, A. P. (2019) "Optimization-based study of the location of park-and-ride facilities", Transportation Planning Technology, 42(3), pp. 201-226. https://doi.org/10.1080/03081060.2019.1576380

Charypar, D., Nagel, K. (2005) "Generating complete all-day activity plans with genetic algorithms", Transportation, 32(4), pp. 369-397. https://doi.org/10.1007/s11116-004-8287-y

Du, B., Wang, D. Z. W. (2014) "Continuum modeling of park-and-ride services considering travel time reliability and heterogeneous commuters - A linear complementarity system approach", Transportation Research Part E: Logistics Transportation Review, 71, pp. 58-81. https://doi.org/10.1016/j.tre.2014.08.008

Duncan, M., Christensen, R. K. (2013) "An analysis of park-and-ride provision at light rail stations across the US", Transport Policy, 25, pp. $148-157$. https://doi.org/10.1016/j.tranpol.2012.11.014

Etzioni, S., Hamadneh, J., Elvarsson, A. B., Esztergár-Kiss, D., Djukanovic, M., Neophytou, S. N., Sodnik, J., Polydoropoulou, A., Tsouros, I., Pronello, C., Thomopoulos, N., Shiftan, Y. (2020) "Modeling cross-national differences in automated vehicle acceptance", Sustainability, 12(22), Article number: 9765. https://doi.org/10.3390/su12229765
Fagnant, D. J., Kockelman, K. M., Bansal, P. (2016) "Operations of Shared Autonomous Vehicle Fleet for Austin, Texas, Market", Transportation Research Record: Journal of the Transportation Research Board, 2536(1), pp. 98-106. https://doi.org/10.3141/2536-12

Farhan, B., Murray, A. T. (2005) "A GIS-Based Approach for Delineating Market Areas for Park and Ride Facilities", Transactions in GIS, 9(2), pp. 91-108. https://doi.org/10.1111/j.1467-9671.2005.00208.x

Farhan, B., Murray, A. T. (2008) "Siting park-and-ride facilities using a multi-objective spatial optimization model", Computers \& Operations Research, 35(2), pp. 445-456. https://doi.org/10.1016/j.cor.2006.03.009

Garber, N. J., Hoel, L. A. (2014) "Traffic \& highway engineering", Cengage Learning, Stamford, CT, USA.

Golbabaei, F., Yigitcanlar, T., Bunker, J. (2020) "The role of shared autonomous vehicle systems in delivering smart urban mobility: A systematic review of the literature", International Journal of Sustainable Transportation, 15(10), pp. 731-748. https://doi.org/10.1080/15568318.2020.1798571

Hamadneh, J., Esztergár-Kiss, D. (2019) "Impacts of Shared Autonomous Vehicles on the Travelers' Mobility", In: 6th International Conference on Models and Technologies for Intelligent Transportation Systems (MT-ITS), Cracow, Poland, pp. 1-9. https://doi.org/10.1109/mtits.2019.8883392

Hamadneh, J., Esztergár-Kiss, D. (2021) "Potential Travel Time Reduction with Autonomous Vehicles for Different Types of Travellers", Promet - Traffic \& Transportation, 33(1), pp. 61-76. https://doi.org/10.7307/ptt.v33i1.3585

HCSO (Hungarian Central Statistical Office) (2018) "Population Census in 2011", [online] Available at: http://www.ksh.hu/nepszamlalas/ copyright_eng [Accessed: 09 February 2021].

Hensher, D. A., Greene, W. H. (2003) "The Mixed Logit model: The state of practice", Transportation, 30, pp. 133-176. https://doi.org/10.1023/A:1022558715350

Hörl, S., Erath, A., Axhausen, K. W. (2016) "Simulation of autonomous taxis in a multi-modal traffic scenario with dynamic demand", Working paper, Arbeitsberichte Verkehrs- und Raumplanung, 1184, pp. 1-14. https://doi.org/10.3929/ethz-b-000118794

Horni, A., Nagel, K., Axhausen, K. W. (eds.) (2016) "The Multi-Agent Transport Simulation MATSim", Ubiquity Press, London, UK. https://doi.org/10.5334/baw

JOSM (2018) "Java OpenStreetMap Editor" [online] Available at: https://josm.openstreetmap.de/wiki/Download\#Java [Accessed: 09 February 2021]

Leich, G., Bischoff, J. (2019) "Should autonomous shared taxis replace buses? A simulation study", Transportation Research Procedia, 41, pp. $450-460$. https://doi.org/10.1016/j.trpro.2019.09.076

Litman, T. A. (2017) "Autonomous vehicle implementation predictions: Implications for Transport Planning", Victoria Transport Policy Institute Victoria, British Columbia, Canada.

Maciejewski, M. (2016) "Dynamic Transport Services", In: Maciejewski, M., Horni, A., Nagel, K., Axhausen, K. (eds.) The Multi-Agent Transport Simulation MATSim, Ubiquity Press, London, UK. https://doi.org/10.5334/baw.23 
Memon, I. A., Madzlan, N., Talpur, M. A. H., Hakro, M. R, Chandio, I. A. (2014) "A Review on the Factors Influencing the Park-and-Ride Traffic Management Method", Applied Mechanics and Materials, 567, pp. 663-668. https://doi.org/10.4028/www.scientific.net/amm.567.663

Menon, N., Barbour, N., Zhang, Y., Pinjari, A. R., Mannering, F. (2019) "Shared autonomous vehicles and their potential impacts on household vehicle ownership: An exploratory empirical assessment", International Journal of Sustainable Transportation, 13(2), pp. 111-122.

https://doi.org/10.1080/15568318.2018.1443178

Mesa, J. A., Ortega, F. A. (2001) "Park-and-Ride Station Catchment Areas in Metropolitan Rapid Transit Systems", In: Pursula, M., Niittymäki, J. (eds.) Mathematical methods on optimization in transportation systems, Springer, Boston, MA, USA, pp. 81-93. https://doi.org/10.1007/978-1-4757-3357-0_5

Meyer, J., Becker, H., Bösch, P. M, Axhausen, K. W. (2017) "Autonomous vehicles: The next jump in accessibilities?", Research in Transportation Economics, 62, pp. 80-91. https://doi.org/10.1016/j.retrec.2017.03.005

Mokhtarian, P. L., Salomon, I. (2001) "How derived is the demand for travel? Some conceptual and measurement considerations", Transportation Research Part A: Policy and Practice, 35(8), pp. 695-719. https://doi.org/10.1016/s0965-8564(00)00013-6

Musk, E. (2020) "The future development of artificial intelligence technology China", presented at World Artificial Intelligence Conference, Webinar, Date of Conference (July 09-11 2020). [online] Available at: http://waic-sail.com/en/ [Accessed: 09 February 2021]

Nicolai, T. W. (2013) "Integrating an urban simulation model with a travel model", PhD thesis, Berlin Institute of Technology (TU Berlin).

Olia, A., Razavi, S., Abdulhai, B., Abdelgawad, H. (2018) "Traffic capacity implications of automated vehicles mixed with regular vehicles", Journal of Intelligent Transportation Systems: Technology, Planning, and Operations, 22(3), pp. 244-262. https://doi.org/10.1080/15472450.2017.1404680

Ortega, J., Hamadneh, J., Esztergár-Kiss, D., Tóth, J. (2020a) "Simulation of the Daily Activity Plans of Travelers Using the Park-and-Ride System and Autonomous Vehicles: Work and Shopping Trip Purposes", Applied Sciences, 10(8), Article number: 2912. https://doi.org/10.3390/app10082912
Ortega, J., Tóth, J., Péter, T. (2020b) "Mapping the catchment area of park and ride facilities within urban environments", ISPRS International Journal of Geo-Information, 9(9), Article number: 501. https://doi.org/10.3390/ijgi9090501

Parkhurst, G. (2000) "Influence of bus-based park and ride facilities on users' car traffic", Transport policy, 7(2), pp. 159-172. https://doi.org/10.1016/s0967-070x(00)00006-8

Pudāne, B., Molin, E. J. E., Arentze, T. A., Maknoon, Y., Chorus, C. G. (2018) "A Time-use Model for the Automated Vehicle-era", Transportation Research Part C: Emerging Technologies, 93, pp. $102-114$ https://doi.org/10.1016/j.trc.2018.05.022

Simoni, M. D., Kockelman, K. M., Gurumurthy, K. M., Bischoff, J. (2018) "Congestion pricing in a world of self-driving vehicles: An analysis of different strategies in alternative future scenarios", Transportation Research Part C: Emerging Technologies, 98, pp. 167-185. https://doi.org/10.1016/j.trc.2018.11.002

Song, Z., He, Y., Zhang, L. (2017) "Integrated planning of park-and-ride facilities and transit service", Transportation Research Part C: Emerging Technologies, 74, pp. 182-195. https://doi.org/10.1016/j.trc.2016.11.017

Spillar, R. J. (1997) "Park-and-Ride Planning and Design Guidelines", Parsons Brinckerhoff Inc., New York, USA.

Steck, F., Kolarova, V., Bahamonde-Birke, F., Trommer, S., Lenz, B. (2018) "How Autonomous Driving May Affect the Value of Travel Time Savings for Commuting", Transportation Research Record: Journal of the Transportation Research Board, 2672(46), pp. 11-20 https://doi.org/10.1177/0361198118757980

Vleugel, J., Bal, F. (2018) "More space and improved living conditions in cities with autonomous vehicles", International Journal of Design \& Nature and Ecodynamics, 12(4), pp. 505-515. https://doi.org/10.2495/dne-v12-n4-505-515

Wiseman, Y. (2017) "Self-driving car-a computer will park for you", International Journal of Engineering \& Technology for Automobile Security, 1(1), pp. 9-16. https://doi.org/10.21742/ijetas.2017.1.1.02 